\title{
Evaluation of inflammatory markers in chronic stroke patients for the selecting drug therapy for the purpose of secondary prevention of stroke
}

\author{
E.Yu. Solovyeva, E.A. Tyutyumova, O.A. Baranova, A.V. Chekanov, A.I. Fedin, A.N. Karneev \\ FGBOU VO Russian National Medical Research University NI Pirogova, Neurology, Moscow, Russia
}

The purpose of this research is to study the endothelial dysfunction process in chronic stroke patients by measuring the levels of endothelial inflammation markers such as myeloperoxidase (MPO), E-selectin, intercellular adhesion molecule-1 (ICAM-1), determined by the ELISA method.

Methods: The research included 53 patients $(21$ females, 32 males; median age: $\mathrm{Me}=65$ ) with atherothrombotic stroke divided into 2 groups: group 1. - patients with stroke from 1 to 6 months $(n=35), 2$. - from 7 to 12 months $(n=18)$. The measurement of MPO, sE-selectin, sICAM-1 was determined by the ELISA method: Hycult biotech (Netherlands), cat. № HK324 (MPO); eBioscince (Austria), cat. № BMS205 (sE-selectin), eBioscince (Austria), cat. № BMS241 (sICAM-1).

Results: All the post-stroke patients had significantly higher MPO and sICAM-1 levels and unexpectedly significantly lower sE-selectin concentration than healthy controls (Table 1). The comparison of two groups of post-stroke patients did not reveal significant differences in the MPO level, however the level of sICAM-1 was significantly higher in the group 2. According to the literature data the SICAM-1 level increases in patients with type 2 diabetes mellitus. After the exclusion of the patients with diabetes the correlation for sICAM-1 remained the same (Image 1).
Conclusions: The obtained results indicate the progression of immune inflammation in post-stroke patients, associated with endothelial dysfunction on the cerebral ischemia background, which persists probably because of the prolonged activity of inflammatory process and the depletion of anti-inflammatory mechanisms. This chronic endothelial inflammation should be corrected in post-stroke patients using the drugs affecting the cell adhesion and endothelial dysfunction to improve cerebral circulation, to improve the disease prognosis, to provide secondary prevention of stroke.

Table 1

\begin{tabular}{|c|c|c|c|c|}
\hline & $\begin{array}{l}\mathrm{MPO}, \\
\mathrm{ng} / \mathrm{ml}\end{array}$ & $\begin{array}{c}\text { sE-selectin, } \\
\mathrm{ng} / \mathrm{ml}\end{array}$ & $\begin{array}{c}\text { sICAM-1, } \\
\mathrm{ng} / \mathrm{ml}\end{array}$ & $p$-value \\
\hline $\begin{array}{l}\text { Control } \\
\text { group }\end{array}$ & $\begin{array}{c}\mathrm{Me}=89 \\
{[L Q=30,7 ;} \\
\cup Q=103,9]\end{array}$ & $\begin{array}{l}\mathrm{Me}=50,5 \\
{[\mathrm{LQ}=17,5 ;} \\
\mathrm{UQ}=88,1]\end{array}$ & $\begin{array}{l}M e=230,3 \\
{[L Q=129,9 ;} \\
\cup Q=297,4]\end{array}$ & \\
\hline $\begin{array}{l}\text { Post- } \\
\text { stroke } \\
\text { patients } \\
\text { group }\end{array}$ & $\begin{array}{c}\mathrm{Me}=544 \\
{[\mathrm{LQ}=490 ;} \\
\cup Q=684,8]\end{array}$ & $\begin{array}{c}\mathrm{Me}=24 \\
{[\mathrm{LQ}=20,2 ;} \\
\cup Q=34,2]\end{array}$ & $\begin{aligned} \mathrm{Me} & =3584,2 \\
{[\mathrm{LQ}} & =2973,5 ; \\
\mathrm{UQ} & =4353,7]\end{aligned}$ & $p<0,05$ \\
\hline
\end{tabular}

Image 1.

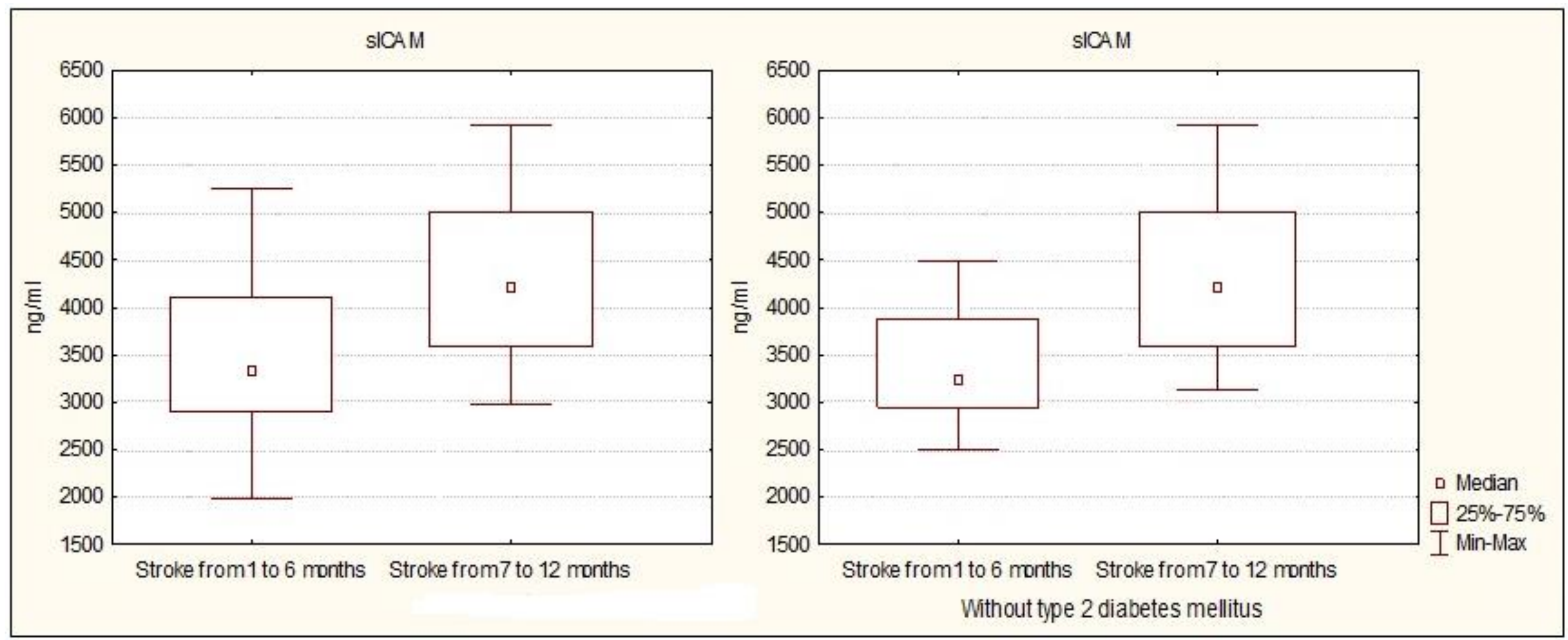

